\title{
Desert Research and Technology Studies Exposure of Lotus Coated Electrodynamic Shield samples
}

\author{
Danielle V. Margiotta ${ }^{1}$ and Kristin R. McKittrick ${ }^{2}$ \\ NASA Goddard Space Flight Center, 8800 Greenbelt Road, Greenbelt, MD, USA 20771 \\ Stinger Ghaffarian Technologies, Inc., 7701 Greenbelt Road Suite 400, Greenbelt, MD, USA 20770 \\ Marcello Rodriguez ${ }^{3}$ \\ NASA Goddard Space Flight Center, 8800 Greenbelt Road, Greenbelt, MD, USA 20771 \\ and \\ Wanda C. Peters ${ }^{4}$ \\ NASA Goddard Space Flight Center, 8800 Greenbelt Road, Greenbelt, MD, USA 20771 \\ and \\ Sharon A. Straka ${ }^{5}$ \\ NASA Goddard Space Flight Center, 8800 Greenbelt Road, Greenbelt, MD, USA 20771 \\ and \\ Craig B. Jones ${ }^{6}$ \\ Stinger Ghaffarian Technologies, Inc., 7701 Greenbelt Road Suite 400, Greenbelt, MD, USA 20770
}

The Lotus dust mitigation coating and the electrodynamic shield (EDS) are two new technologies currently being developed by NASA as countermeasures for addressing dust accumulation for long-duration human space exploration. These combined technologies were chosen by the Habitation Demonstration Unit (HDU) program for desert dust exposure at the Desert Research and Technologies Studies (D-RaTS) test site in Arizona. Characterization of these samples was performed prior to, during and post D-RaTS exposure.

\section{Nomenclature}

$a \quad=$ solar absorptance

\footnotetext{
${ }^{1}$ Thermal Coatings Engineer, Contamination and Coatings Engineering Branch, Code 546.

${ }^{2}$ Thermal Coatings Engineer, Contamination and Coatings Engineering Branch, Code 546.

${ }^{3}$ Thermal Coatings Engineer, Contamination and Coatings Engineering Branch, Code 546.

${ }^{4}$ Associate Chief Division Head, Mechanical Systems Division, Code 540.

${ }_{6}^{5}$ Contamination Group Lead, Contamination and Coatings Engineering Branch, Code 546.

${ }^{6}$ Thermal Coatings Engineer, Contamination and Coatings Engineering Branch, Code 546.
} 


\section{Introduction}

A s part of NASA's Desert Research and Technology Studies (D-RaTS) event in Black Lava Flow, AZ, active and passive dust mitigation technologies were tested. From August 31 - September 15, 2010 Electrodynamic Dust Shields (EDS) and Lotus coated samples were exposed to the desert dust environment. These samples were mounted on the large scale Pressurized Excursion Module (PEM) door. The PEM is part of the Habitation Demonstration Unit (HDU) project "which seeks to investigate and demonstrate concepts, technologies, and architectures for lunar exploration"1.

Goddard Space Flight Center (GSFC) provided the Lotus coating for the EDS technology supplied by Kennedy Space Center (KSC). The Lotus coating is a passive dust mitigation technology that relies on intrinsic self-cleaning and anti-contamination properties. The EDS is an active dust mitigation technology which uses a traveling electrodynamic wave to direct particles to a specific location ${ }^{1}$. The combination of these two technologies was tested at the D-RaTS site and later characterized by GSFC Coatings engineers.

\section{Background}

At D-RaTS the symbiotic relationship between the EDS and Lotus technologies was investigated. The EDS technology utilizes a metalized grid in between two laminated 5 mil Kapton ${ }^{\mathrm{TM}}$ sheets. When the EDS is contaminated, an electric field can be applied through a two-phase electrode configuration. This electric field charges the dust particles. The dust particles then move in a particular direction off the surface of the shield ${ }^{1}$. The Lotus coating technology has the ability to repel water and dust due to its unique surface architecture. This architecture creates a super-hydrophobic boundary which aids in reducing the surface energy and area that is required for particle adhesion ${ }^{2}$. Through the addition of the Lotus coating to the EDS surface, dust mitigation properties are enhanced. The Lotus coating reduces the amount of dust that can attach to the EDS surface thus optimizing the EDS's particle removal abilities.

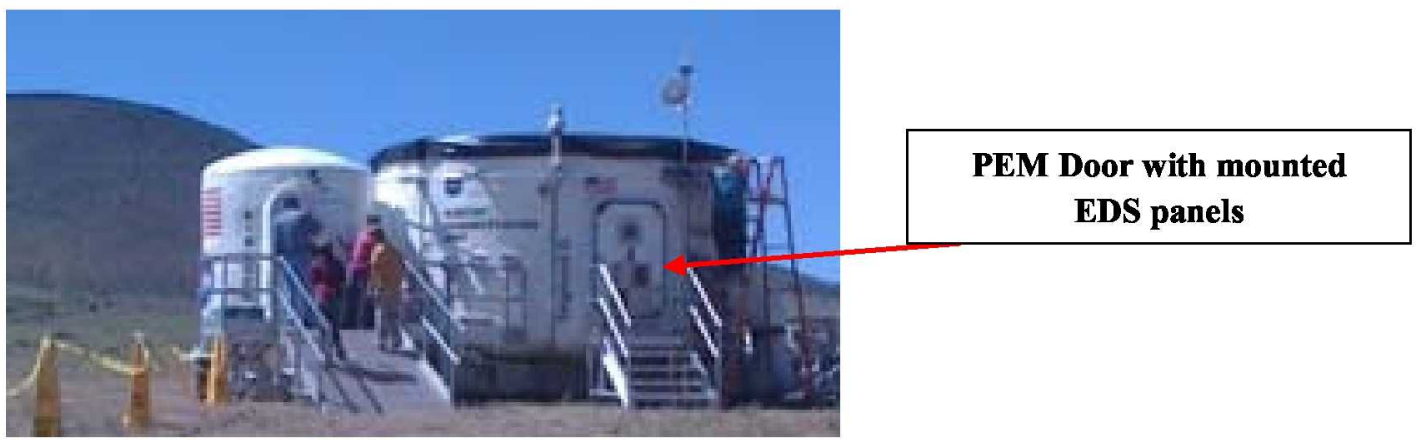

Figure 1: PEM door with mounted EDS panels at D-RaTS site

The D-RaTS demonstration involved placing four 8x10-inch panels on door 4 of the PEM. The panels were exposed to the uncontrolled elements in at the D-RaTS site for 14 days. Through a connected power supply, KSC activated the EDS panels daily during operations. GSFC Coatings Engineers traveled twice to D-RaTS at the beginning and end of exposure. During these visits GSFC performed microscopic imaging and reflection measurements on the four panels during the 1st, 10th, and 11th days of the 14 day exposure. At the conclusion of the D-Rats exposure, the PEM was transported back to Johnson Space Center (JSC). Once at JSC the panels were removed from the PEM door and hand delivered back to GSFC for post exposure testing.

Prior to integration on the PEM door, the panels were subjected to a series of tests for characterization. The same tests were performed once the panels were received back to GSFC after D-RaTS exposure. The tests included solar absorptance measurements, confocal imaging and goniometer contact angle measurements. Digital images were also taken throughout testing and exposure for documentation. While at D-RaTS only solar absorptance measurements and microscopy imaging was performed due to the portable nature of these instruments. 
Two Lotus coated EDS panels, one uncoated EDS panel and one Lotus control panel were mounted on the PEM door at JSC on March 30, 2010. The PEM door with the samples mounted at JSC, is depicted in Figure 2. A protective window was placed in front of the samples to be removed at D-RaTS.

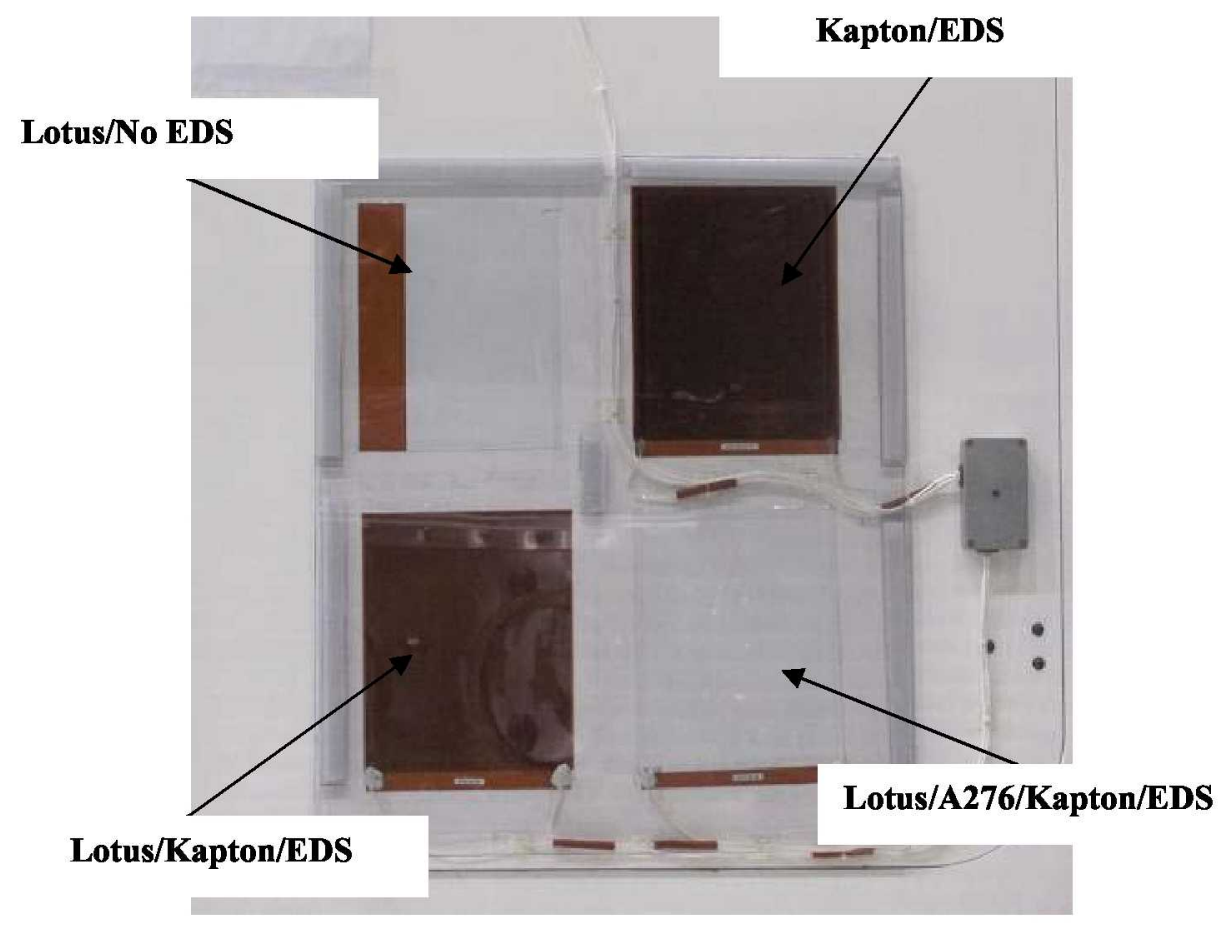

Figure 2: March 2010 Installation at JSC

Between the time of installation and transport to D-RaTS, the PEM was moved outside to the JSC rock yard where dry runs were perfromed. During this time the panels were exposed to humidity. Upon arrival to D-RaTS the humidity exposure was discovered. The leads on all of the EDS panels had corroded and no longer functioned. The exposure did not have any visible effect on the performance of the Lotus coating. KSC removed two of the EDS panels on August 30, 2010 and GSFC removed the third panel on September 1, 2010. Two of the replacement panels provided by KSC did not have the Lotus coating. The replacement EDS panel supplied GSFC was a back-up from the March 2010 installation which did have the Lotus coating. Table 1 contains the serial numbers and coating configurations of the replaced EDS panels. Figure 3 shows the locations of the replaced EDS panels on the PEM door. Figure 4 shows the control coating configuration.

Table 1: PEM Door Serial Numbers and Coating Configurations

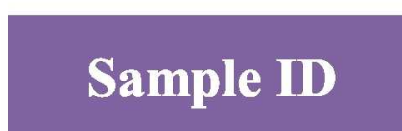

\begin{tabular}{|c|c|c|}
\hline EDS & Coating & Lotus \\
\hline Yes & None & Yes \\
\hline Yes & None & No \\
\hline Yes & None & No \\
\hline No & A276 & No \\
\hline No & A276 & Yes \\
\hline No & No & No \\
\hline
\end{tabular}

\begin{tabular}{|c|}
\hline 2010_03_08A \\
\hline 2010_03_24_D3 \\
\hline 2010_03_24_D2 \\
\hline Control 1 \\
\hline Control 2 \\
\hline Control 3 \\
\hline
\end{tabular}




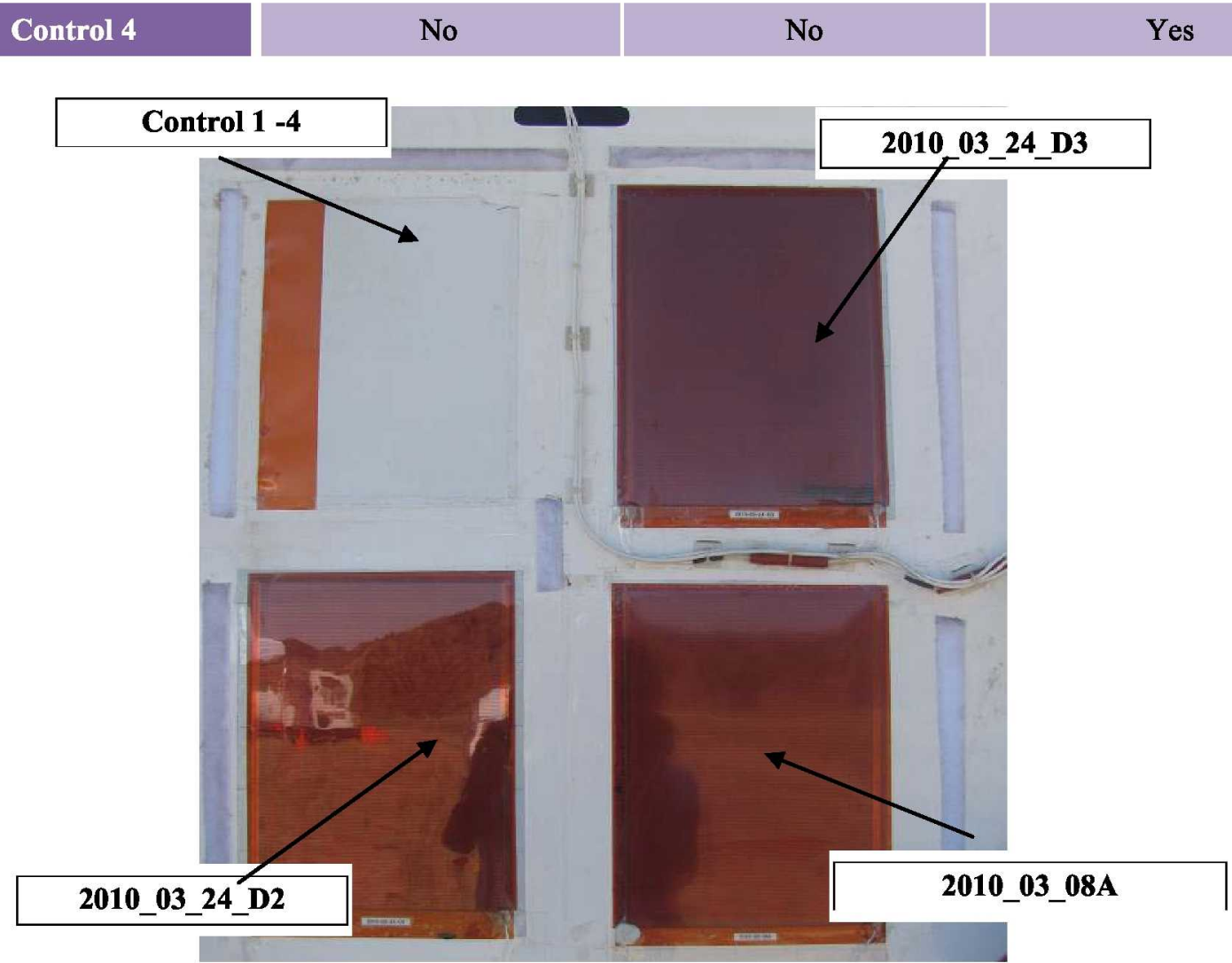

Figure 3: September 2010 D-RaTS EDS Replacement

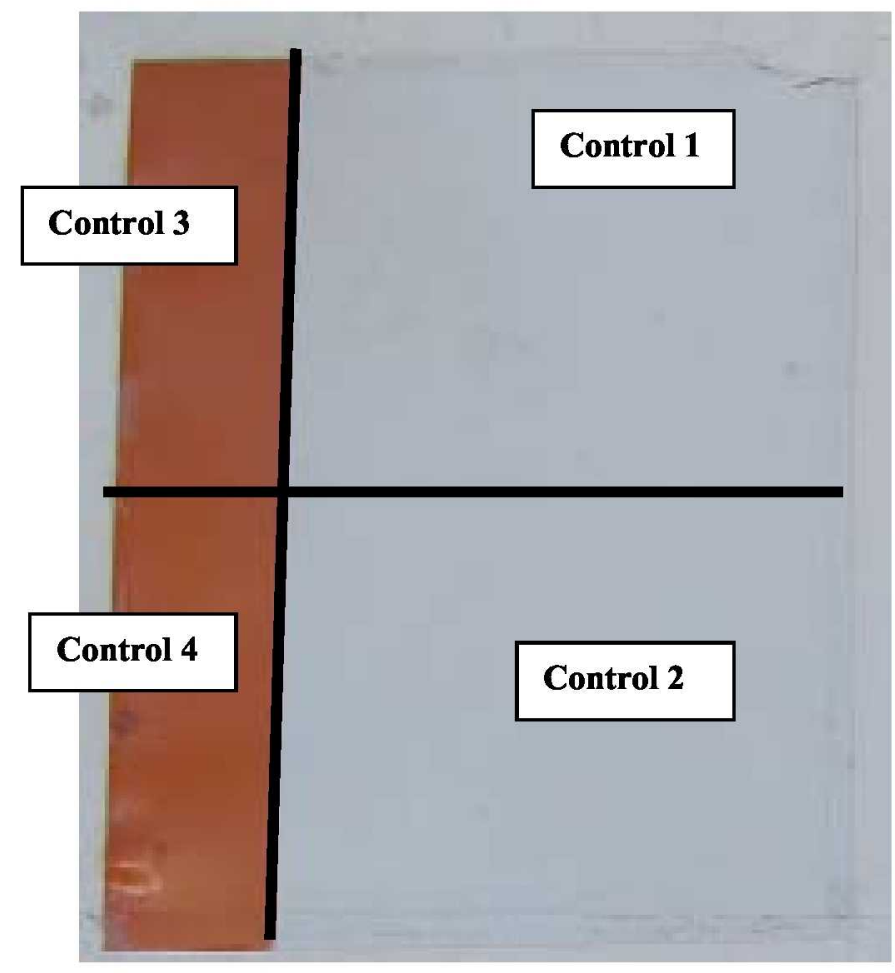

Figure 4: Controls 1 through 4 


\section{Test Method}

\section{A. REFLECTIVITY}

The AZ Technology's LPSR-300 instrument was used to perform the reflectance measurements and solar absorptance calculations. The reflectance measurements followed the ASTM E903-82 standard test method. The LPSR-300 measures the reflectance of the sample's surface for a spectral range of $250 \mathrm{~nm}$ to $2800 \mathrm{~nm}$, at a $15^{\circ}$ angle of incidence. The instrument's measurement of accuracy is \pm 0.02 for $\alpha$ values.

\section{B. CONTACT ANGLE}

Contact angle is measured using a VCA-1000 Optima Goniometer made by Analytical Technology Group (AST). The operator uses the provided syringe to drop a single droplet of regular tap water onto the surface of the sample. A video camera records an image of the droplet. The system uses a software package to determine the contact angle, the surface energy, and surface tension through automatic and dynamic calculations. An assumption of the droplet geometry, whether it is spherical or ellipsoidal, is made based on the image. With this information, the angle in which the liquid contacts the solid surface can be calculated. A coating is determined to be hydrophobic when the contact angle is greater than $90^{\circ}$ and a super-hydrophobic surface is defined as having a contact angle larger than $150^{\circ}$. Water was the only liquid used in our testing however other liquids, such as solvents, may be used as well.

\section{CONFOCAL IMAGING}

Confocal imaging is performed on an Olympus LEXT OLS-3100IR laser based confocal microscope. This microscope allows for nondestructive 3D image capturing of surfaces. The confocal imager has a capability to magnify up to $1400 \mathrm{x}$ with a resolution of $15 \mathrm{~nm}$.

\section{DINO-LITE IMAGING}

The Dino-Lite AMK4012-C200 digital microscope includes a fully portable LCD monitor for both live imaging and/or image capture. It is specifically designed for field applications and has a 200X magnification with an AV/TV (NTSC) display interface for instant real time, live images.

\section{Results}

Prior to integration onto the PEM door in March 2010, solar absorptance measurements, contact angle measurements and confocal imaging was performed at GSFC on 2010_03_08A and Controls 1-4. These tests were performed again at GSFC in October 2010 after the two week D-RaTS exposure. During the D-RaTS exposure in September 2010, solar absorptance measurements were performed and microscopic images were taken utilizing a portable microscope called the Dino-Lite. Both of these instruments are portable and could be easily transported to the D-RaTS site. The results will be explained in detail below.

\section{A. CONTACT ANGLE MEASUREMENTS}

Pre-exposure contact angle measurements were performed on March 26, 2010 at one location on each panel to minimize any degradation of the samples which might occur. Post-exposure contact angle measurements were performed on November 2, 2010. Pre and post exposure results from the contact angle measurements are shown in Table 2. Figures 5 through 14 are images taken with the VCA-1000 Optima Goniometer video camera of the water droplet on each panel. The left contact angle corresponds to the angle made between the left side of the water droplet and the surface of the panel. The right contact angle corresponds to the angle made between the right side of the water droplet and the surface of the panel.

The pre-exposure measurements exhibited that all panels with the Lotus coating demonstrated super-hydrophobic properties. The measured contact angles of the panels were greater than or equal to $150^{\circ}$. The contact angles of 2010_03_08A and Controls 2 and 4 were significantly greater than Controls 1 and 3. 
The post-exposure measurements showed a degradation of the super-hydrophobic properties of 2010_03_08A. In Table 2 this measurement is marked with **. A large range of measured contact angles was observed over the surface of this EDS panel. A visible inspection of 2010_03_08A showed a haze on a large portion of the surface. In these hazy areas hydrophilic properties with contact angles less than $90^{\circ}$ were observed. In some cases contact angles were too small to be measured. Hydrophobic properties were demonstrated in the non-hazy areas. Contact angles of $135^{\circ}$ were observed however this is under the super-hydrophobic threshold of $150^{\circ}$ that was observed in the pre-exposure measurements. The post-exposure contact angle measurements performed on Controls 3 and 4 also showed decreased contact angles. Controls 1 and 2 did not show a significant change from pre to post exposure.

Table 2: Contact Angle Measurements

\begin{tabular}{|c|c|c|c|c|}
\hline \multirow{2}{*}{ Sample ID } & \multicolumn{2}{|c|}{ Pre-Exposure } & \multicolumn{2}{c|}{ Post-Exposure } \\
\cline { 2 - 5 } & Lefit & Right & Left & Right \\
\hline 2010_03_08A & $150^{\circ}$ & $150^{\circ}$ & $* * 135^{\circ}$ & $* * 135^{\circ}$ \\
\hline Control 1 & $85^{\circ}$ & $83^{\circ}$ & $83^{\circ}$ & $82^{\circ}$ \\
\hline Control 2 & $148^{\circ}$ & $148^{\circ}$ & $151^{\circ}$ & $151^{\circ}$ \\
\hline Control 3 & $76^{\circ}$ & $76^{\circ}$ & $64^{\circ}$ & $62^{\circ}$ \\
\hline Control 4 & $150^{\circ}$ & $149^{\circ}$ & $96^{\circ}$ & $96^{\circ}$ \\
\hline
\end{tabular}

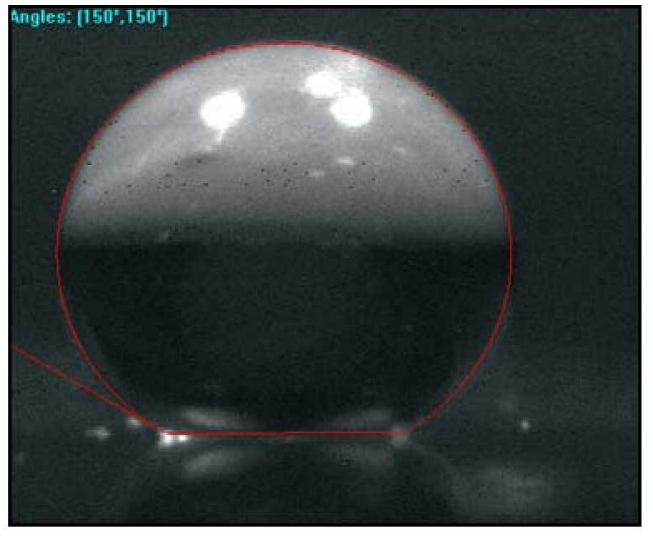

Figure 5: 2010_03_08A - Pre-Exposure Contact Angle

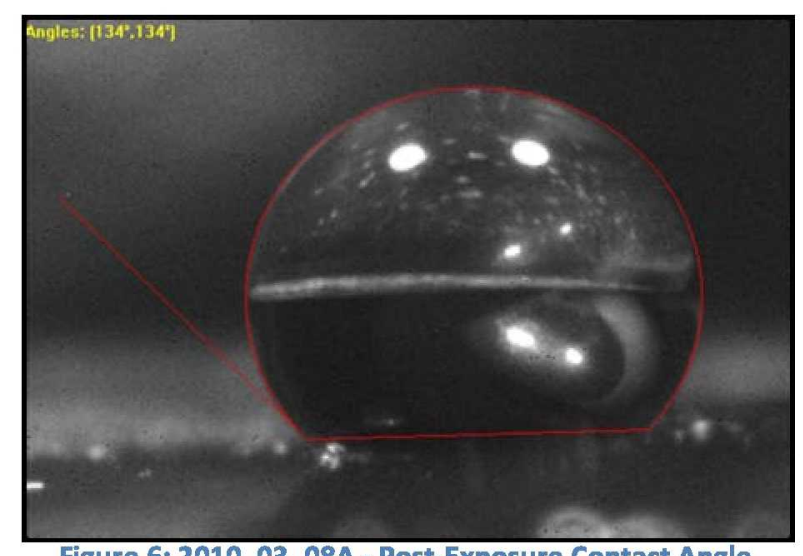

Figure 6: 2010_03_08A - Post-Exposure Contact Angle 


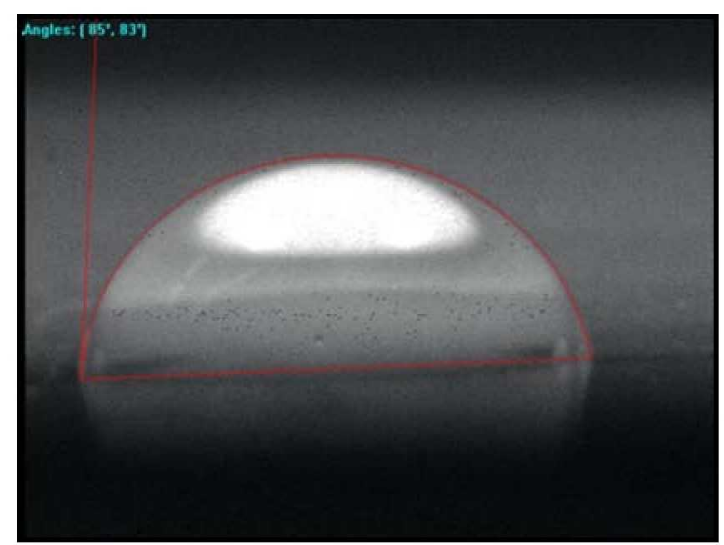

Figure 12: Control 1 - Pre-Exposure Contact Angle

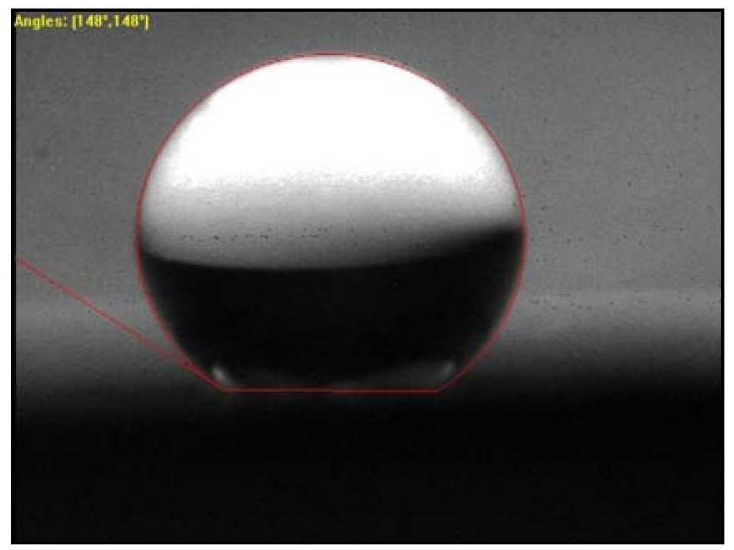

Figure 10: Control 2 - Pre-Exposure Contact Angle

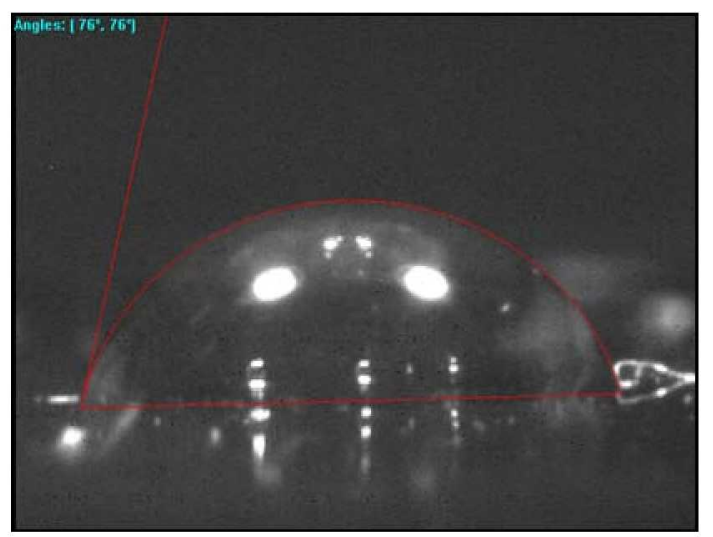

Figure 8: Control 3 - Pre-Exposure Contact Angle

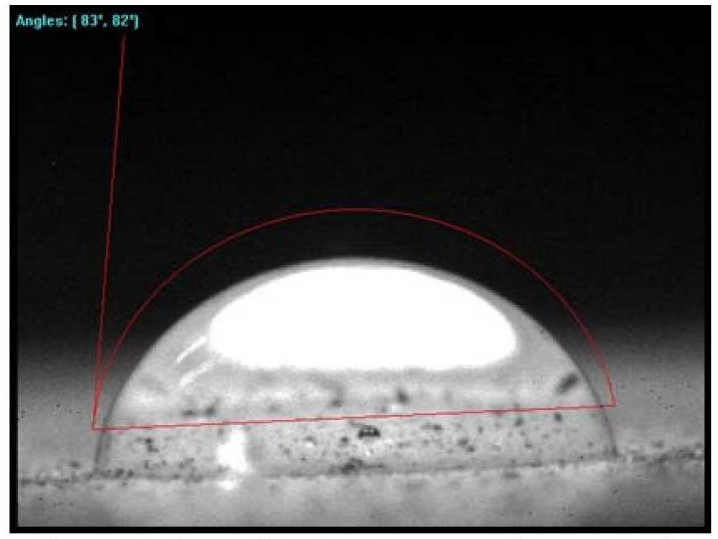

Figure 11: Control 1 - Post-Exposure Contact Angle

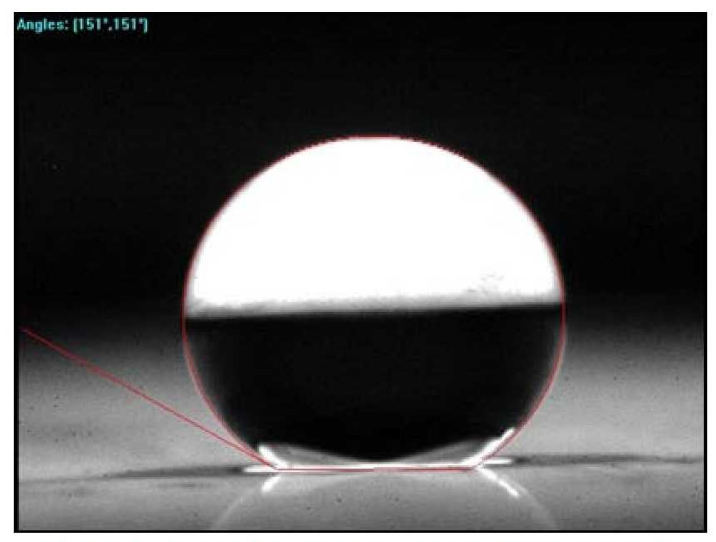

Figure 9: Control 2 - Post-Exposure Contact Angle

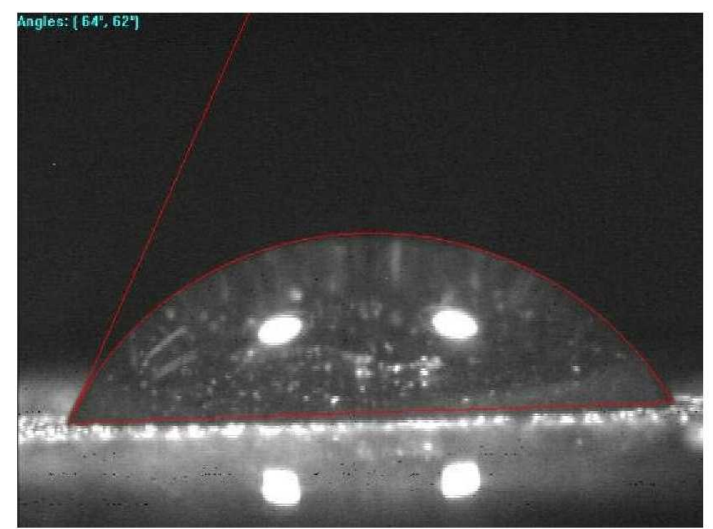

Figure 7: Control 3 - Post-Exposure Contact Angle 


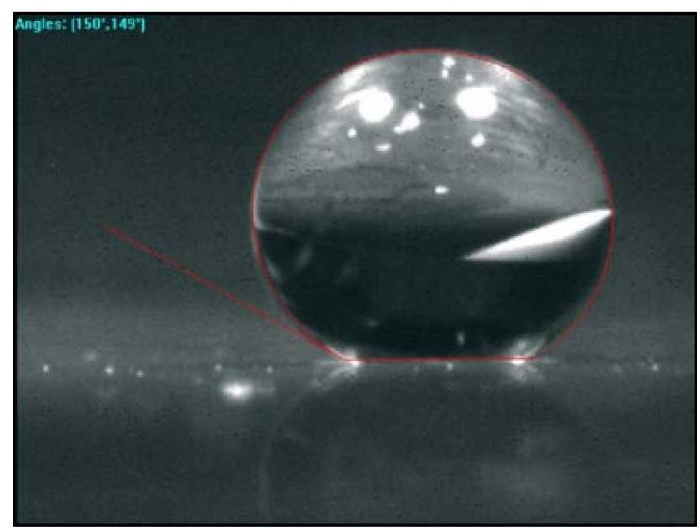

Figure 14: Control 4 - Pre-Exposure Contact Angle

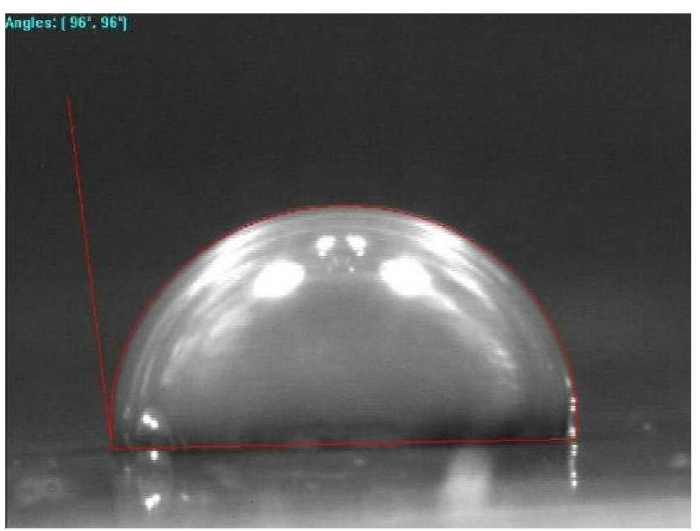

Figure 13: Control 4 - Post-Exposure Contact Angle

\section{B. CONFOCAL IMAGING}

Confocal imaging was performed on 2010_03_08A and Controls 2 and 4 at GSFC prior to integration on the PEM door. This imaging allowed for the capture of $2 \mathrm{D}$ and $3 \mathrm{D}$ images of the surface of the Lotus coated panels for comparison of pre and post D-RaTS exposure.

Figures $15-20$ depict the pre and post 2D and 3D confocal images of the surface of 2010_03 08A at 5X magnification. Figure 15 and 16 show the surface prior to D-RaTS exposure. The surface looks uniform with no irregularities seen in either the Lotus layer or Kapton ${ }^{\mathrm{TM}}$ surface. Figures 17-20 show the post exposure surface of 2010_03_08A. Figure 17 captures the hazy hydrophilic area of the panel. The haze on the surface is similar in nature to a thin layer of dried bubbles. Figure 18 also captures a hydrophilic area of the panel. This area was less hazy than the area seen in Figure 17 however it still displayed decreased contact angles. Figures 19 and 20 capture the hydrophobic area of 2010_03_08A post exposure. This area is similar to the areas seen in Figures 15 and 16 which display 2010_03_08A pre-exposure.

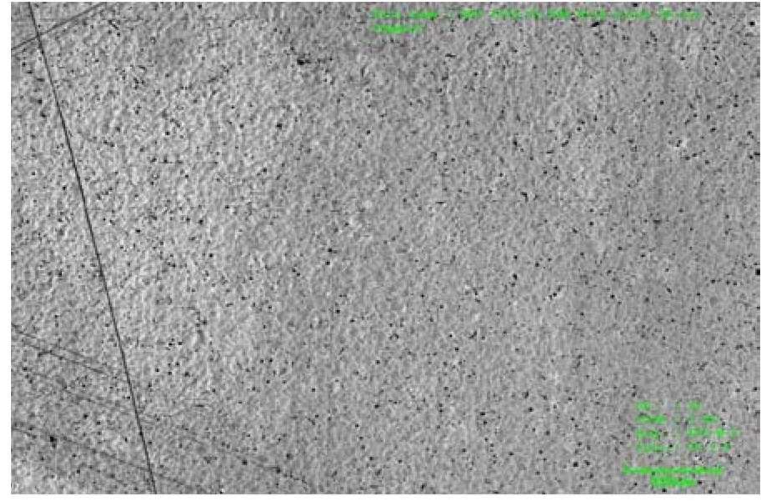

Figure 15: 5X 2D Capture of 2010_03_08A - PreExposure

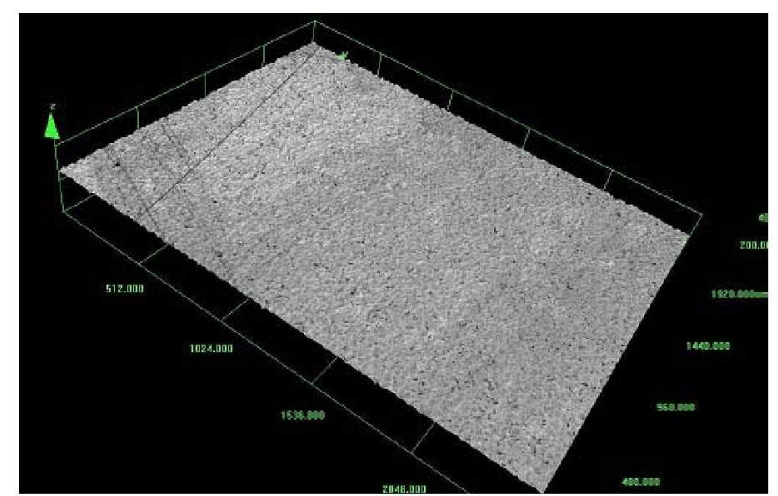

Figure 16: 5X 3D Capture of 2010_03_08A - Pre- 


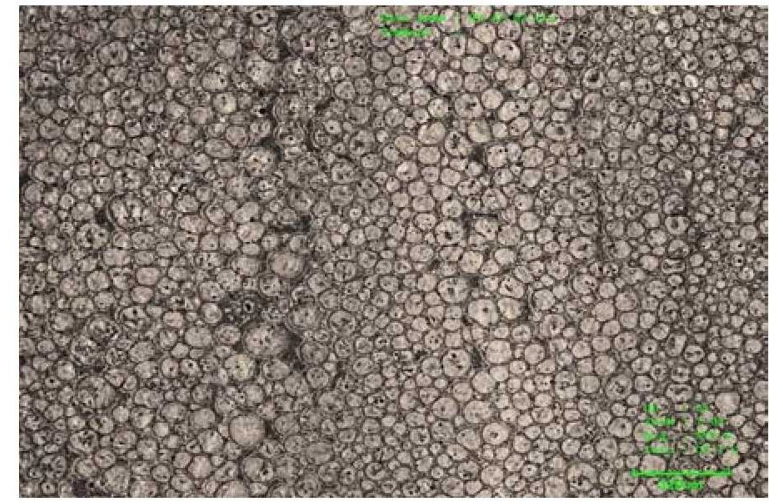

Figure 18: 5X 2D Capture of 2010_03_08A - PostExposure - Streaky Hydrophilic Area

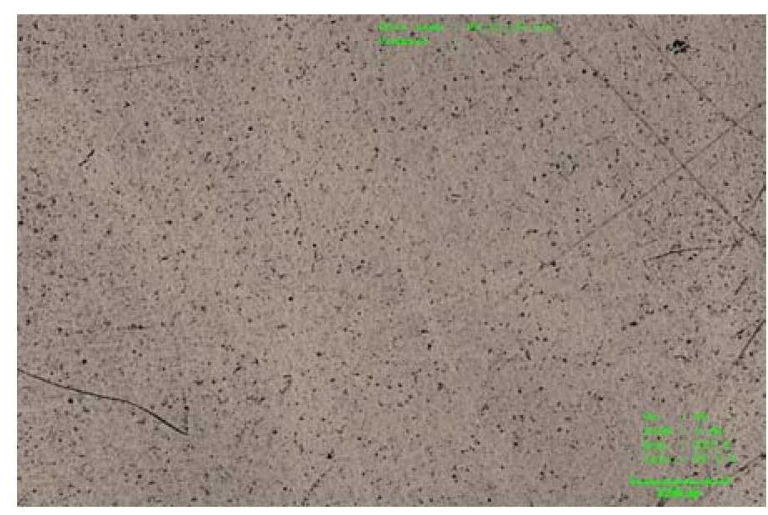

Figure 19: 5X 2D Capture of 2010_03_08A - Post Exposure Hydrophobic Area

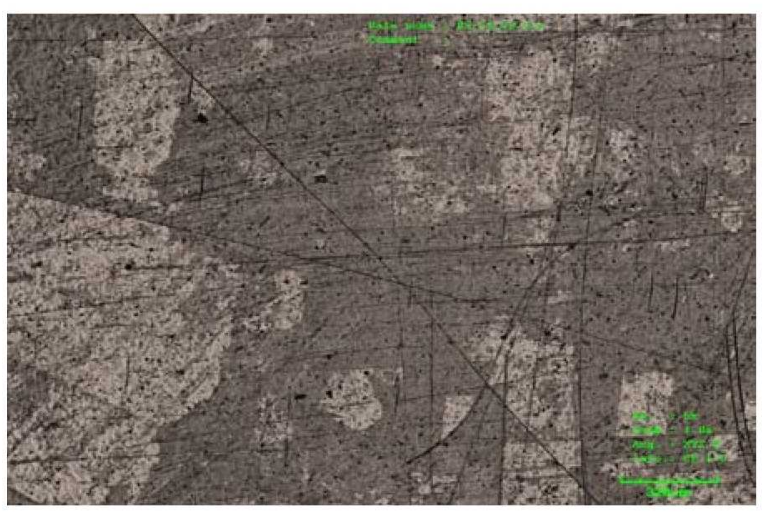

Figure 17: 5X 2D Capture of 2010_03_08A - Post Exposure Hydrophilic Area

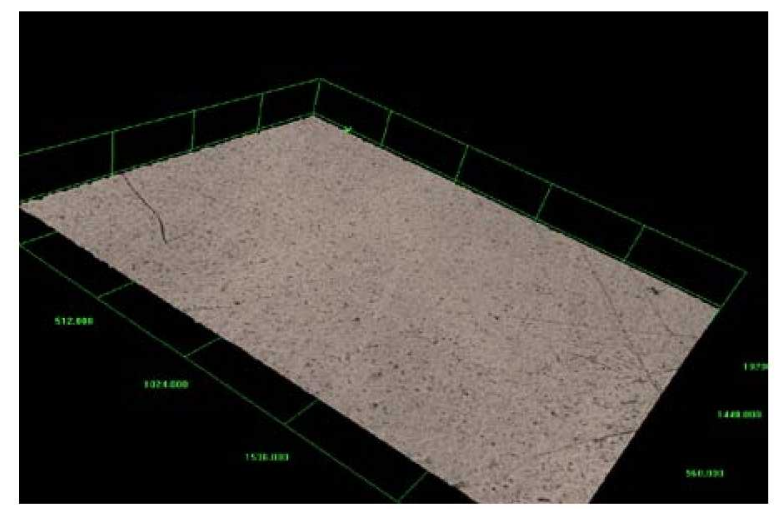

Figure 20: 5X 3D Capture of 2010_03_08A - Post Exposure Hydrophobic Ärea

Figures $21-28$ depict the pre and post exposure 2D and 3D confocal images of Control 2 and 4 at $5 \mathrm{X}$ magnification. Figures $21-24$ show that Control 2 displays no visible irregularities from pre to post exposure. No haze and very little dust was present on the surface. Figures 25 and 26 are images of a representative Lotus coated Kapton $^{\mathrm{TM}}$ sample. Figures 27 and 28 are 2D and 3D images of Control 4 post exposure. Dust residue can be seen in these Figures. This is also evident in the decreased contact angle for Control 4 measured post exposure.

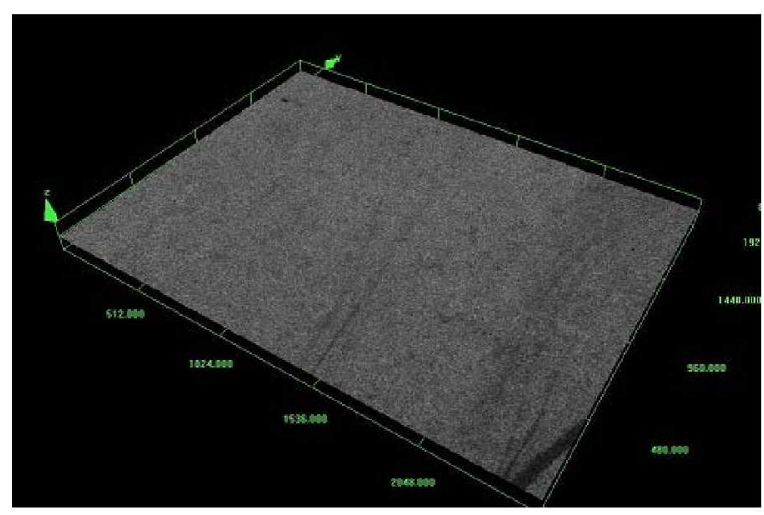

Figure 22: 5X 3D Capture of Control 2-Pre-Exposure

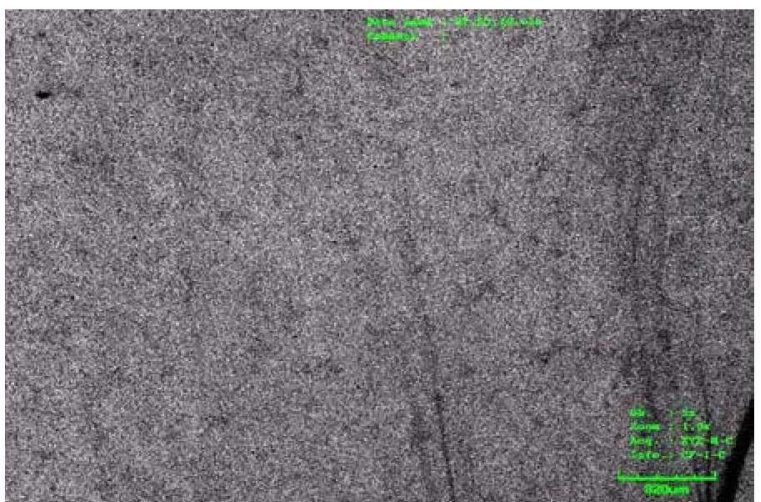

Figure 21: 5X 2D Capture of Control 2 - Pre-Exposure 


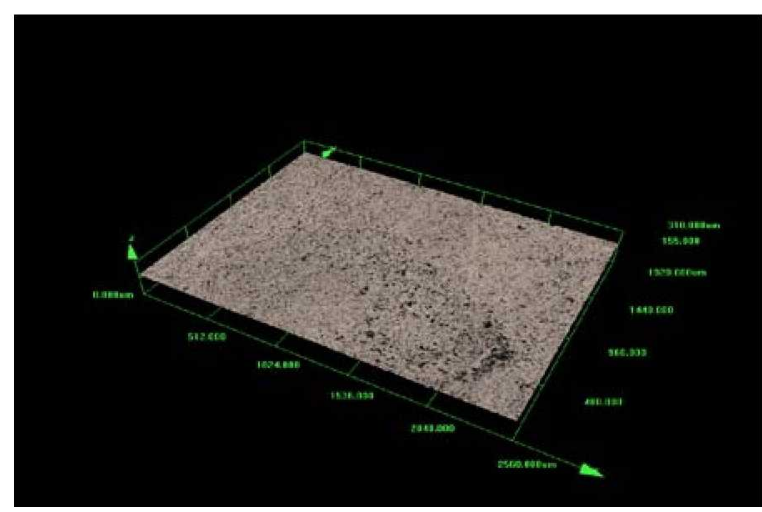

Figure 24: 5X 3D Capture of Control 2 - Post-Exposure

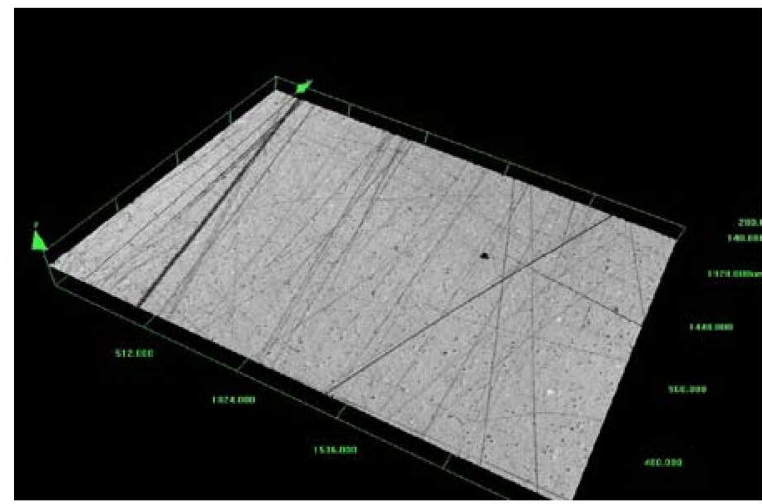

Figure 25: 5X 3D Capture of representative Lotus on Kapton sample - Pre-Exposure

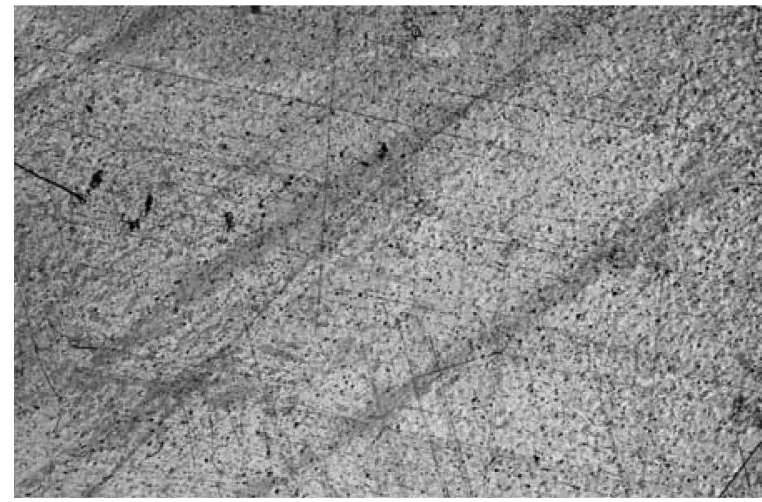

Figure 28: 5X 2D Capture of Control 4 - Post-Exposure

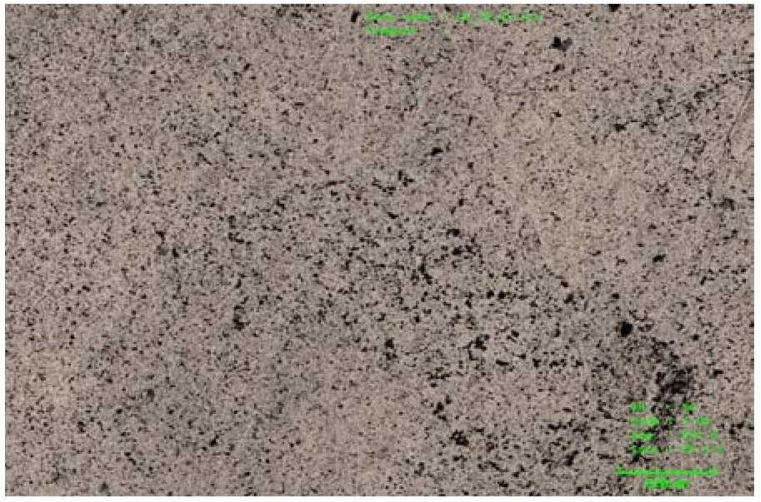

Figure 23: 5X 2D Capture of Control 2 - Post-Exposure

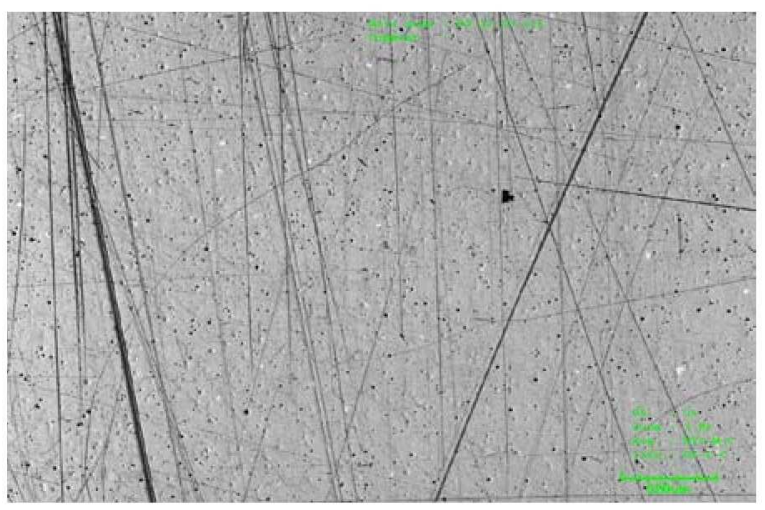

Figure 26: 5X 2D Capture of representative Lotus on Kapton sample - Post-Exposure

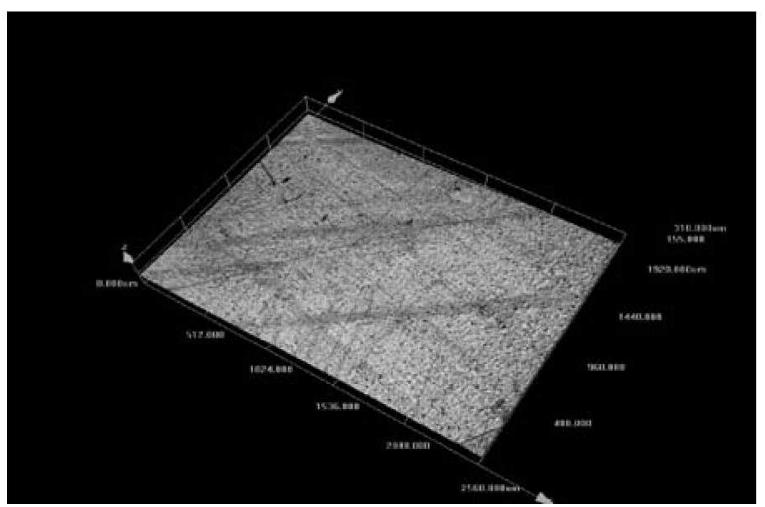

Figure 27: 5X 3D Capture of Control 4 - Post-Exposure 


\section{SOLAR ABSORPTANCE MEASUREMENTS}

Solar absorptance measurements were performed to verify the effectiveness of the Lotus coating and EDS as dust mitigation technologies. An increase in solar absorptance indicates that the surface has been contaminated with dust. Solar absorptance measurements were performed on 2010_03_08A and Controls 1 - 4 in March 2010 prior to integration on the PEM door. Measurements were performed again during two separate trips to D-RaTS in September 2010. Post exposure measurements were completed at GSFC in November 2010.

\section{TRIP \#1}

During the first trip to D-RaTS all of the EDS panels were replaced. Following this replacement, solar absorptance measurements were performed on September 1, 2010 on each of the three EDS panels 2010_03_24-D3, 2010_03_24_D2, 2010_03_8A, and Controls 1 - 4. The measurements performed on the EDS panels will be considered the pre-exposure measurements. The measurements performed on March 22, 2010 will be considered the pre-exposure measurements for Controls 1 - 4 since this was the only panel not replaced. The measurements are all contained in Table 3. In Figure 29 the measurement locations are illustrated with blue dots.

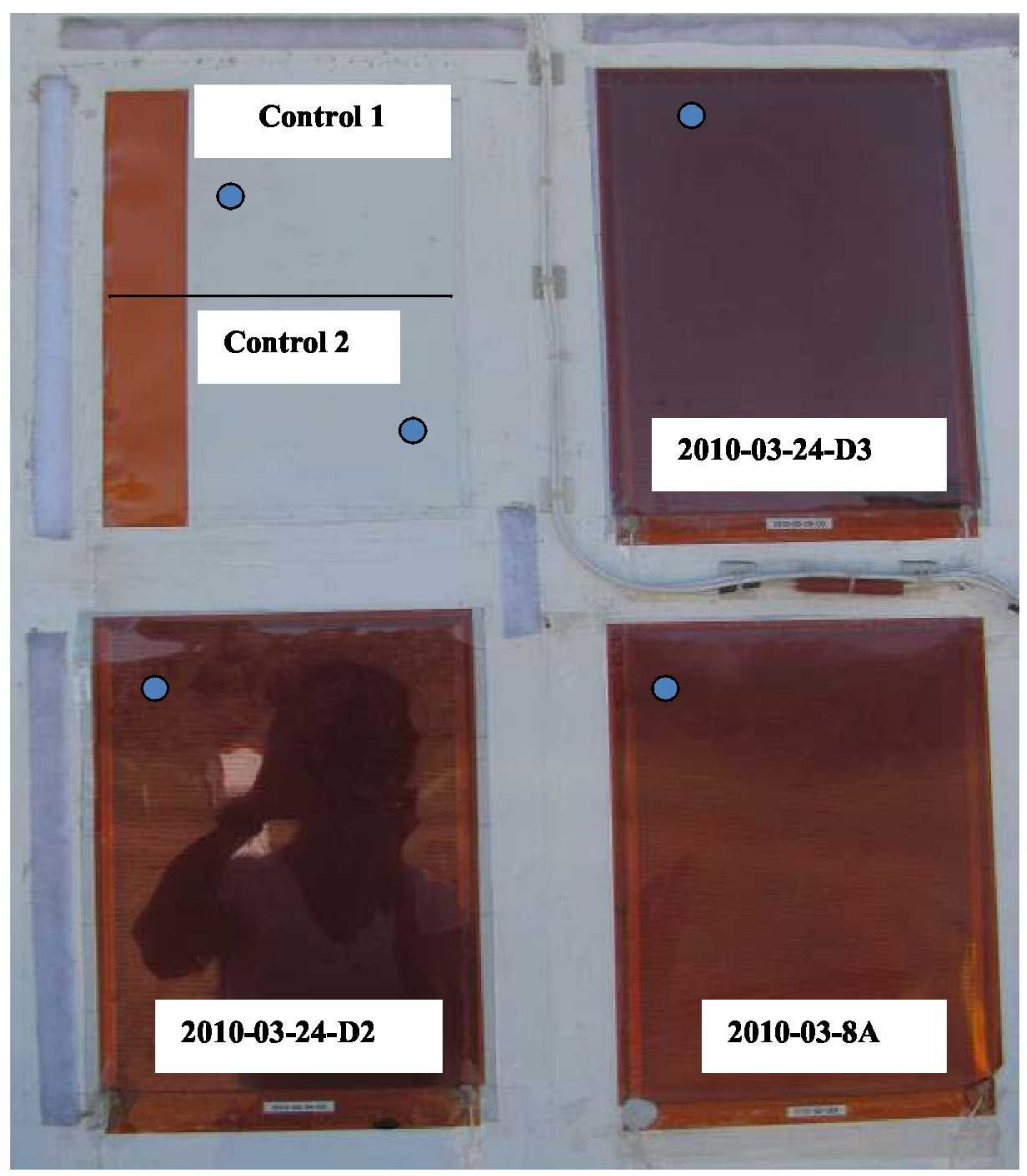

Figure 29: Measurement Locations (Depicted with blue dots)

\section{E. TRIP \#2}

During the second trip solar absorptance measurements were repeated several times in the same locations as indicated in Figure 29. Daily KSC performed dust tests followed by activation of the EDS panels during the D-RaTS exposure. JSC-1 lunar simulant was applied manually to the EDS panels by flicking a brush full of JSC-1 toward the panels before activation ${ }^{3}$. A visual inspection of JSC-1 accumulation was conducted and documented in photographs and microscope images. 
On September 10, 2010, a dust test was performed in which JSC-1 was applied to all three EDS panels and Controls 1 and 2. The EDS technology was then activated to remove the applied dust. Panels 2010_03_24_D3 and 2010_03_24_D2 were then cleaned with a wipe however Panel 2010_03_8A and Controls 1 and 2 were not wiped due to the sensitivity of the Lotus coating. On the morning of September 11,2010 , solar absorptance measurements were performed after overnight exposure. A second dust test was then performed later that same day. JSC-1 was manually applied to the EDS panels. Solar absorptance measurements were then repeated at the respective locations on the panels. The EDS technology was then activated. Solar absorptance measurements were repeated. These measurements are also contained in Table 3. Reflectance curves of each EDS panel and Controls 1 and 2 are depicted in Charts 1 -5. Solar absorptance measurements were not performed on Controls 3 and 4 due to the size of the measurement location.

Table 3: Solar Absorptance Measurements
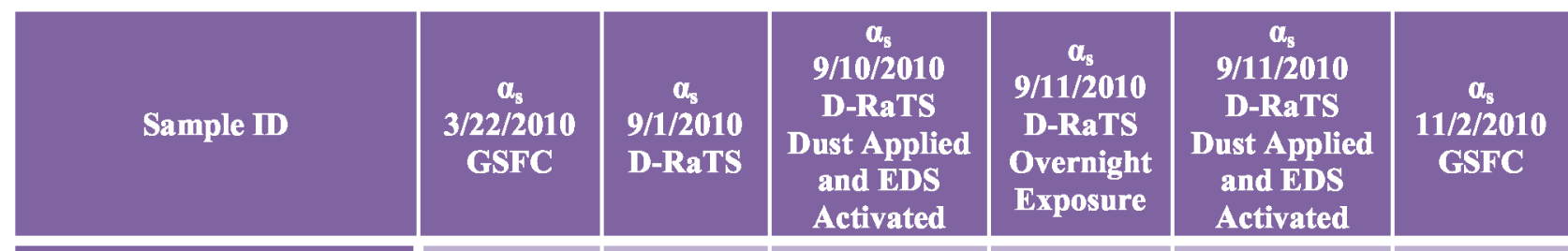

\begin{tabular}{|c|}
\hline 2010-03-24-D3 \\
\hline 2010-03-08A \\
\hline 2010-03-24-D2 \\
\hline Control 1 \\
\hline Control 2 \\
\hline
\end{tabular}

\begin{tabular}{|c|c|c|c|c|c|c|}
\hline- & 0.71 & 0.71 & 0.71 & 0.70 & - \\
\hline- & 0.65 & 0.67 & 0.64 & 0.65 & - \\
\hline- & 0.70 & 0.71 & 0.69 & 0.69 & - \\
\hline 0.26 & 0.30 & - & 0.35 & - & 0.33 \\
\hline 0.25 & 0.28 & - & 0.27 & - & 0.27 \\
\hline
\end{tabular}


Chart 1: 2010_03_08A Reflectance Graph with Solar Absorptance Measurements - EDS/Lotus

Chart 1: 2010_03_08A Reflectance Graph with Solar Absorptance Measurements EDS/Lotus

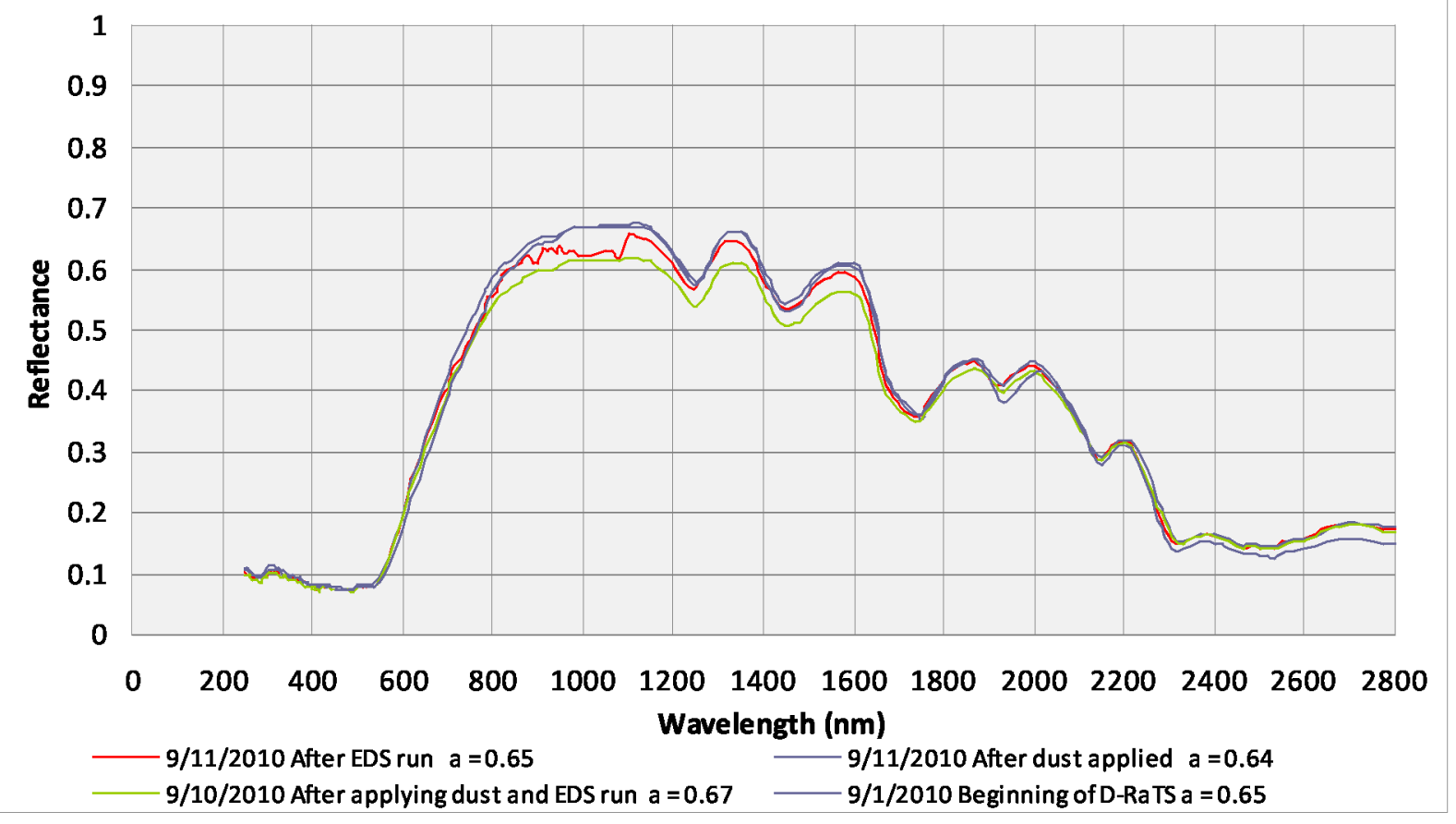

Chart 2: 2010_03_24_D3 Reflectance Graph with Solar Absorptance Measurements - EDS/Kapton ${ }^{\text {TM }}$

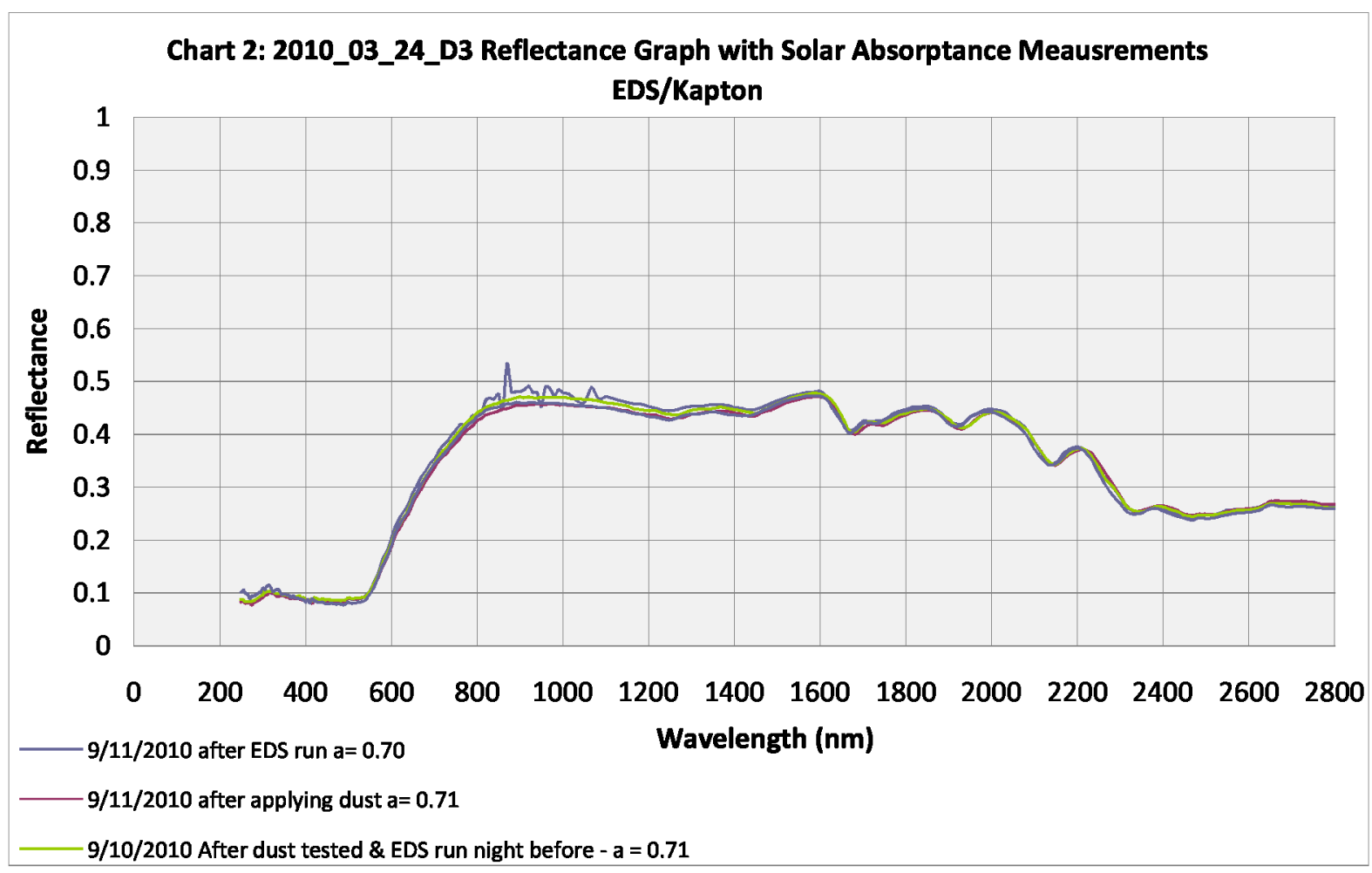


Chart 3: 2010_03_24_D2 Reflectance Graph with Solar Absorptance Measurements - EDS/Kapton ${ }^{\text {TM }}$

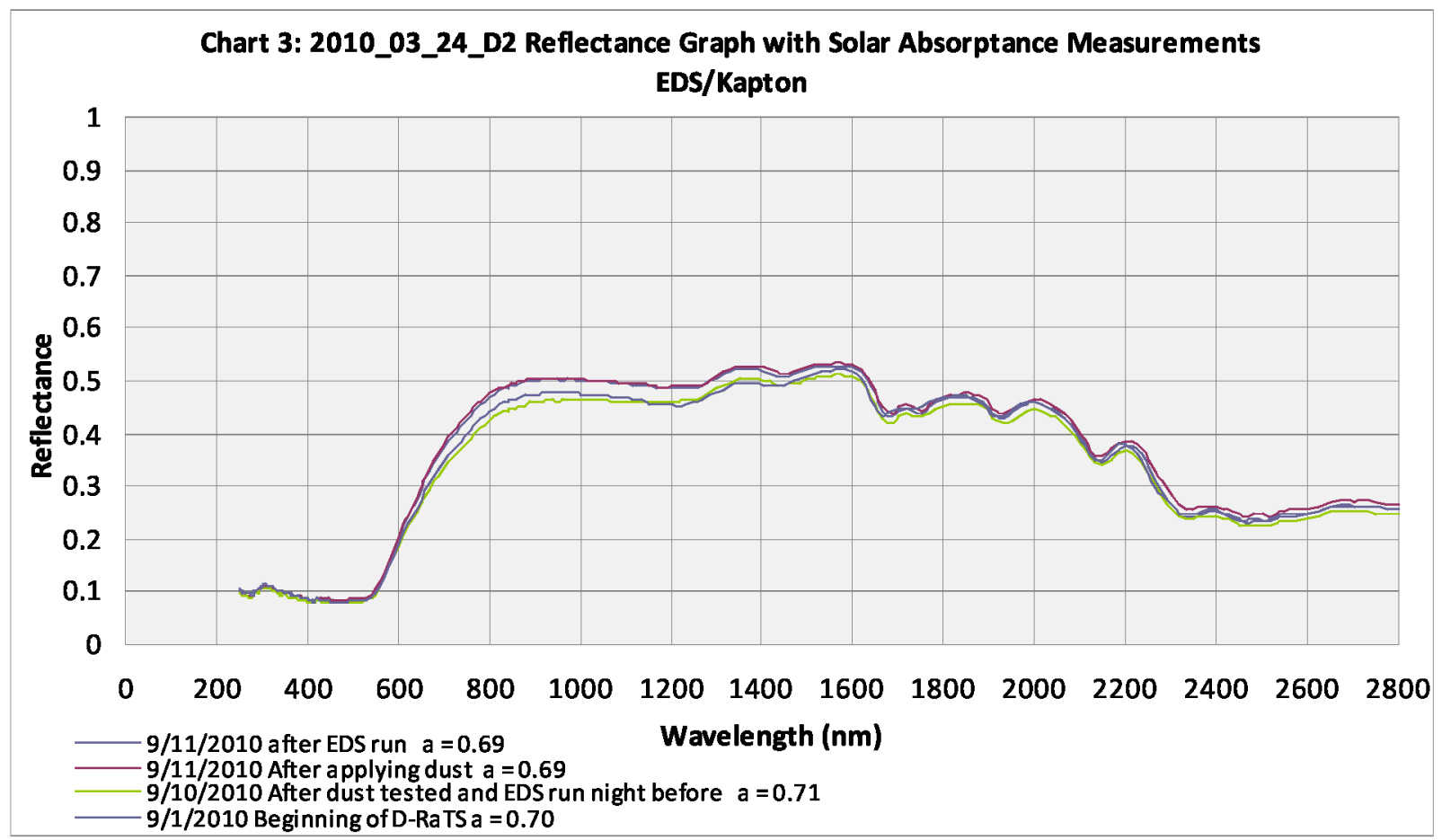

Chart 4: Control 1 Reflectance Graph with Solar Absorptance Measurements

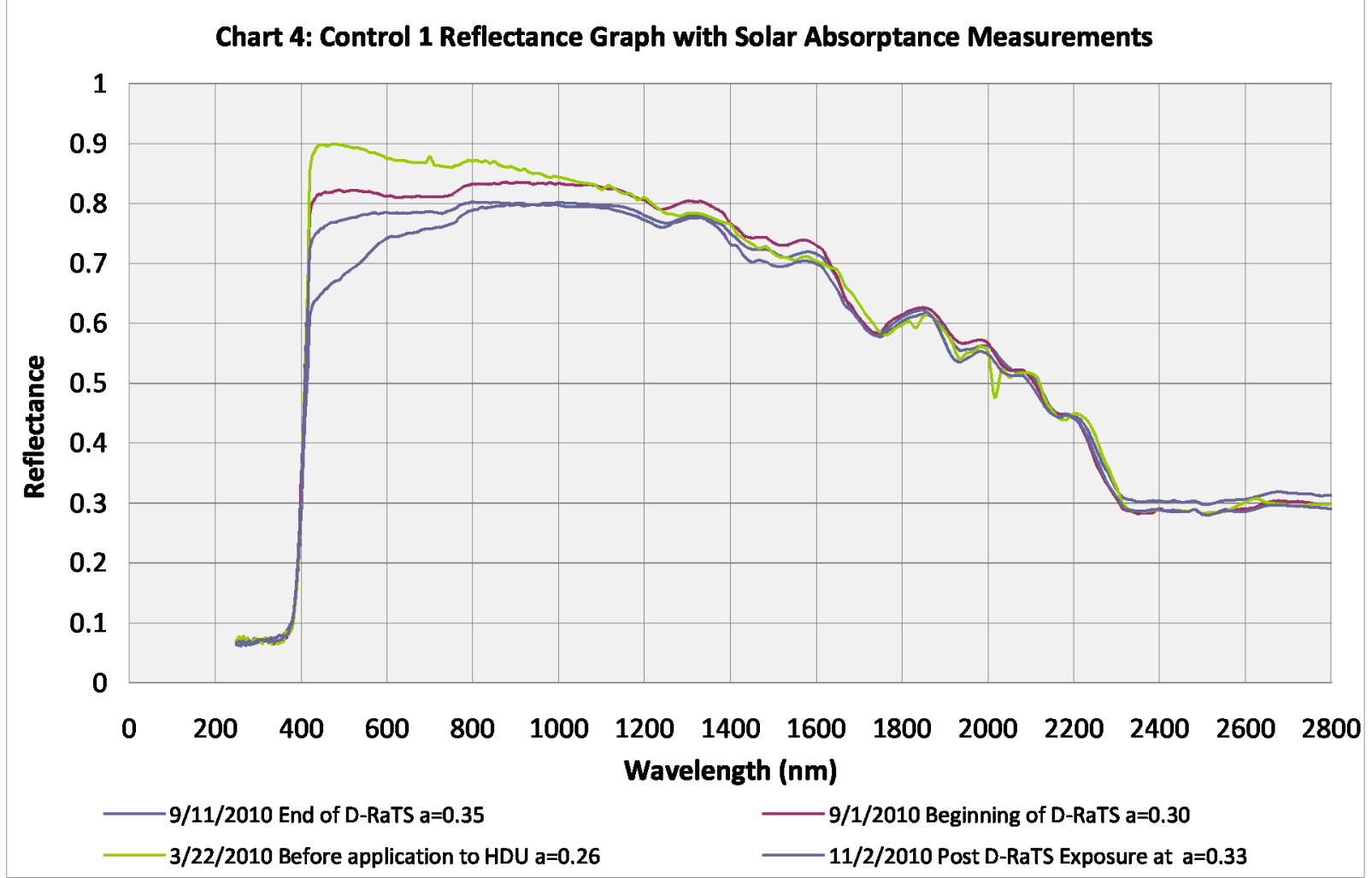




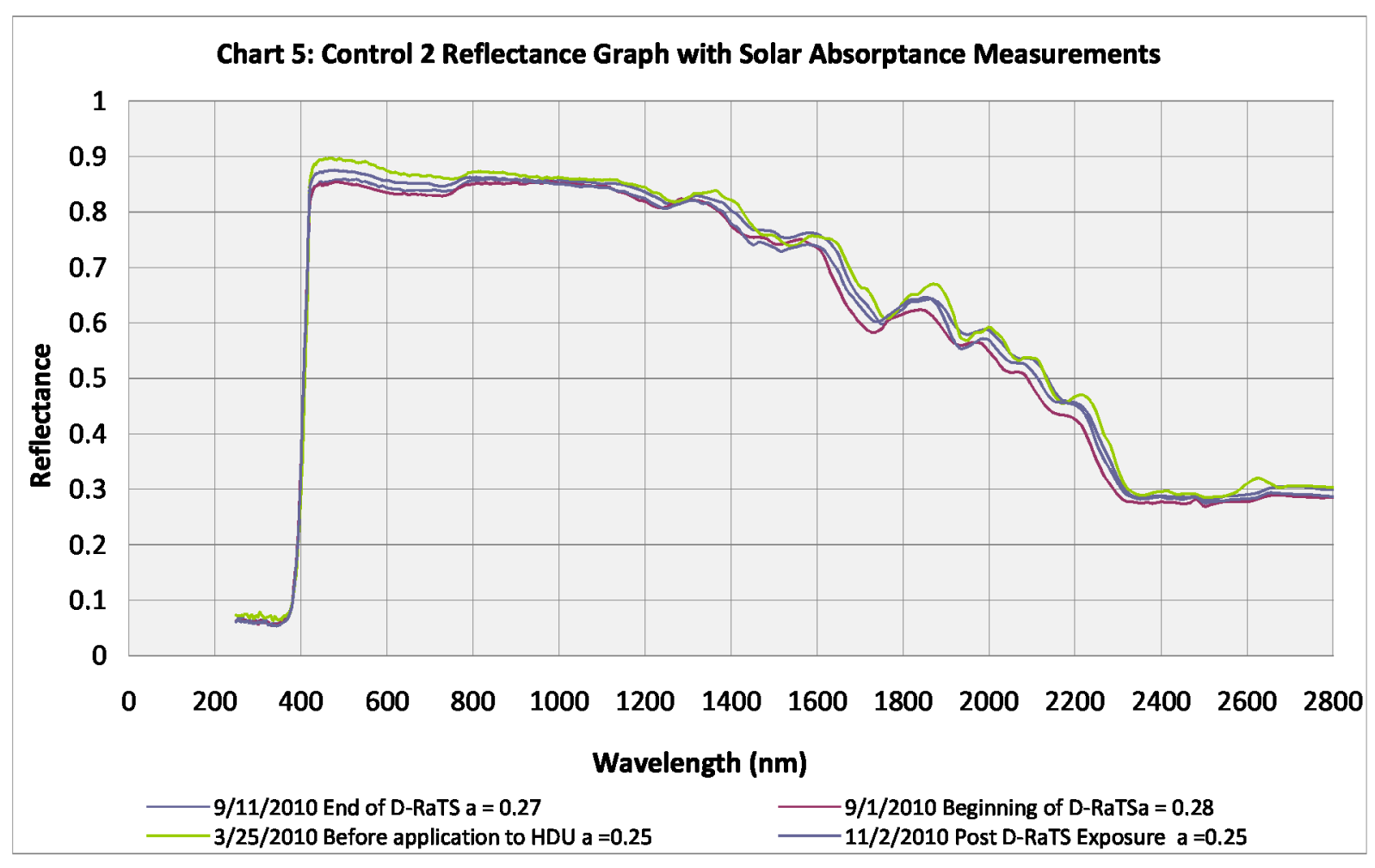

Measurements were taken to look at the overall change in reflectivity throughout the mitigation process. The difference in absorptance between Control 1 and Control 2 is evident and could have a significant effect on thermal control. The $\Delta \alpha$ of Control 1 after almost two weeks of exposure at D-RaTS was 0.09 where as the $\alpha$ of the Control 2 was only 0.02 .

For the EDS panels, measurements were taken before dust was manually applied, after the dust was manually applied, and after activating the EDS technology. The $\Delta \alpha$ was minimal -0.02 or less. This shows that the EDS technology and the Lotus technology have a synergistic relationship. JSC-1 was adequately removed as to not appreciably change the solar absorptance.

\section{F. DINO-LITE}

Using a portable microscope called a Dino-Lite, microscopic images where taken at the same locations where the solar absorptance measurements were performed on the Lotus control and EDS panels. The Dino-Lite has 200X zoom and has the capability to see dust particles down to $100 \mathrm{~nm}$. The Dino-Lite was used for microscopic image capture on both D-RaTS trips because it is a portable instrument that can be easily used in the field.

Due to the replacement of the EDS panels at D-RaTS, the images captured during the first trip will serve as preexposure information. A visual inspection of Controls $1-4$, the only unit not replaced from the March 2010 installation, showed good results for the Lotus coating. Controls 1 and 3 visually showed more dust than Controls 2 and 4. There is a distinct line that divides these regions as seen in Figures 30 and 31. 


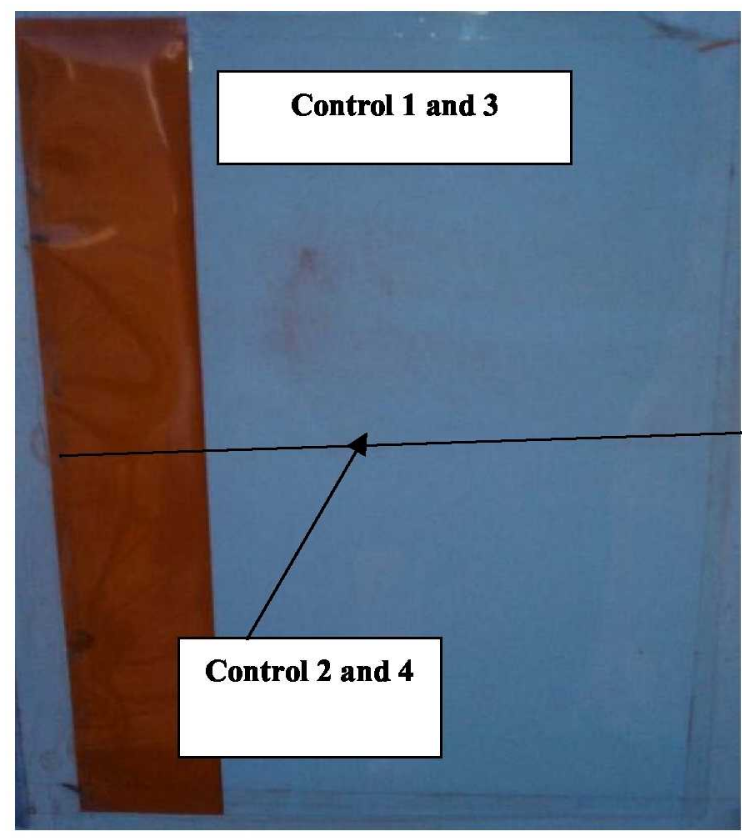

Figure 31: Controls 1 - 4 Taken on 9/11/2010 Trip \#2

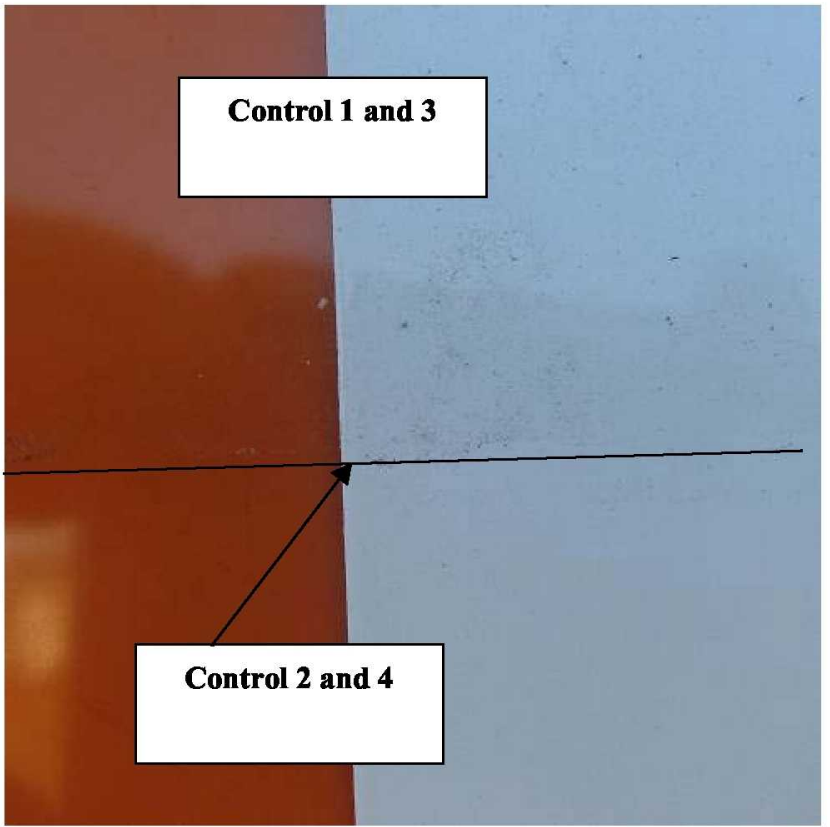

Figure 30: Controls 1 - 4 Taken on 9/1/2010 Trip \#1

The Dino-Lite images that were taken on Controls $1-4$ were helpful to show the difference between the Lotus coated and uncoated areas. The microscopic image Controls 1 and 3 show a larger quantity of particles at larger sizes than those seen on Controls 2 and 4. Figures 32 and 33 compare the microscopic images taken of Control 1 during trip \#1 and \#2. It is easily seen from these images how contaminated the surface became after less than two weeks of exposure at D-Rats. Figures 34 and 35 compare the microscopic images of Control 2 taken during trip \#1 and \#2. Through this observation it shows the significant dust mitigating properties of the Lotus coating.

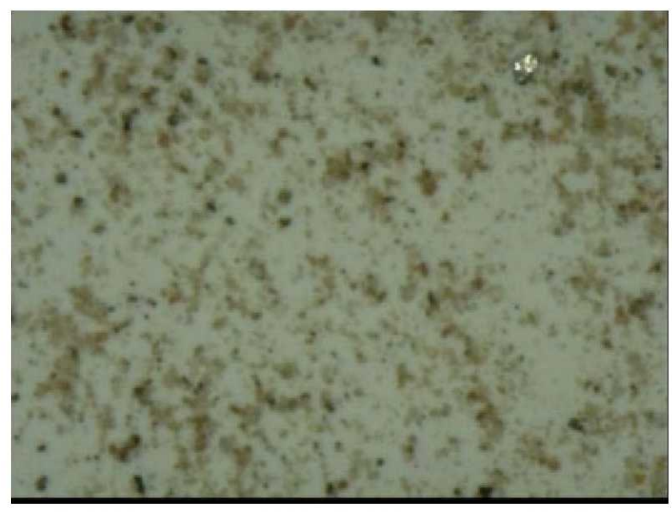

Figure 33: Control 1 - Trip \#2 (9/11/2010)

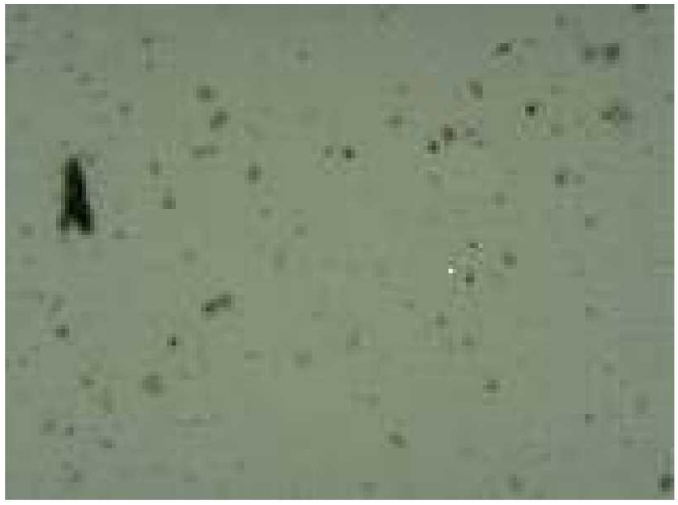

Figure 32: Control 1 - Trip \#1 (9/1/2010) 


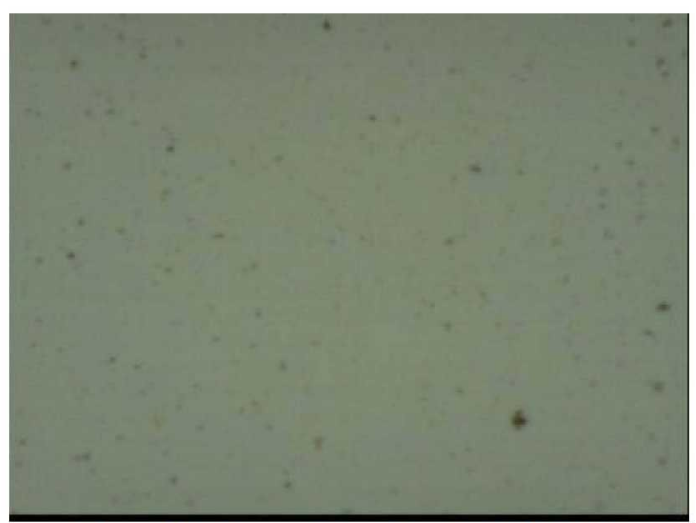

Figure 34: Control 2 - Trip \#2 (9/11/2010)

The same dust mitigating phenomena is seen on all of the EDS panels. Figures $36-41$ compare the panels during trip \#1 and \#2. There was little to no dust accumulation on the surface of the all of the EDS panels over the two week exposure at D-RaTS. It should be noted that 2010_03_08A was not wiped at any point of D-RaTS while 2010_03_24_D2 and 2010_03_24_D3 were.

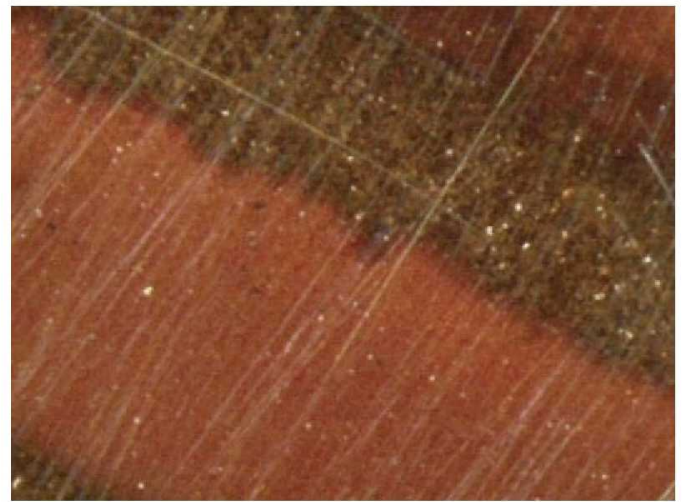

Figure 36: 2010-24-D2 - Trip \#1 (9/1/2010)

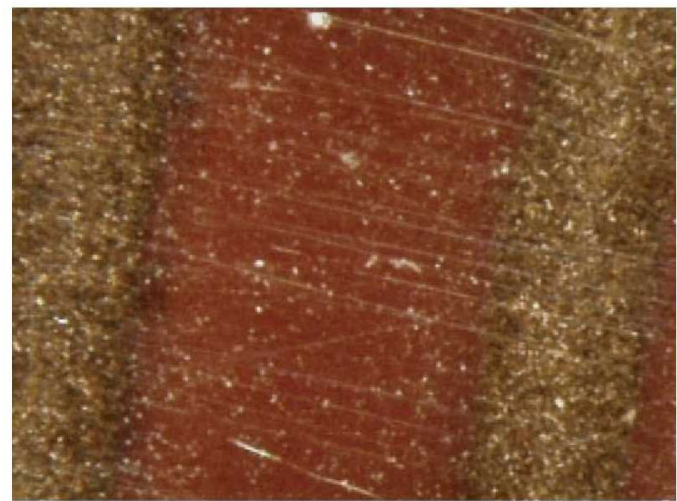

Figure 39: 2010_03_24_D3 - Trip \#1 (9/1/2010)

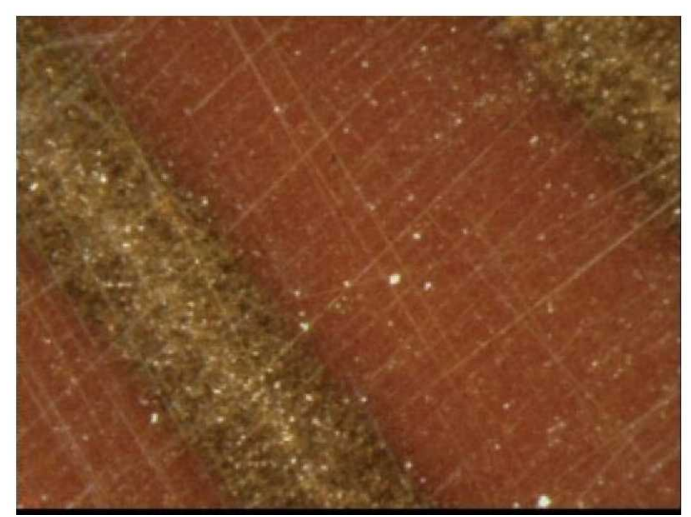

Figure 37: 2010-03-24-D2 - Trip \#2 (9/11/2010)

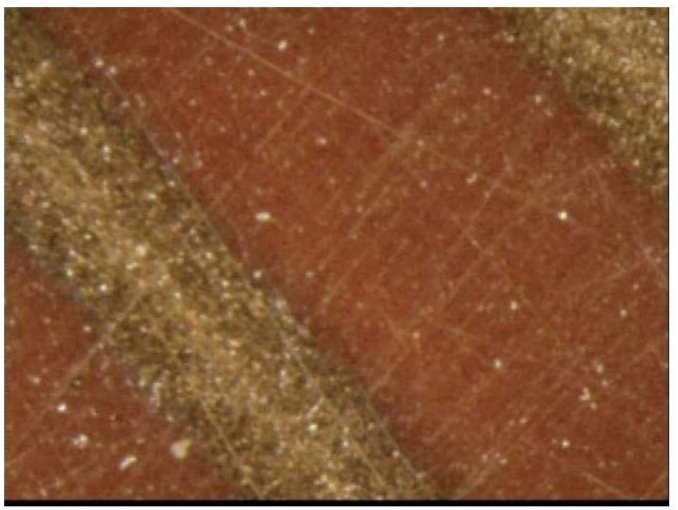

Figure 38: 2010_03_24_D3 - Trip \#2 (9/11/2010) 


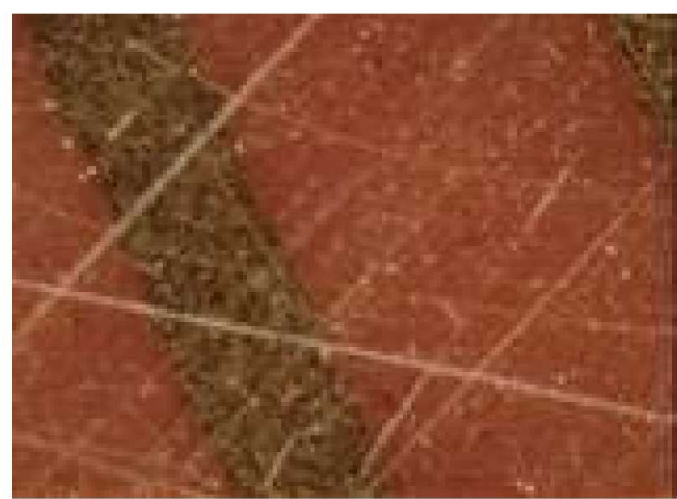

Figure 41: 2010-03-8A - Trip \#1 (9/1/2010)

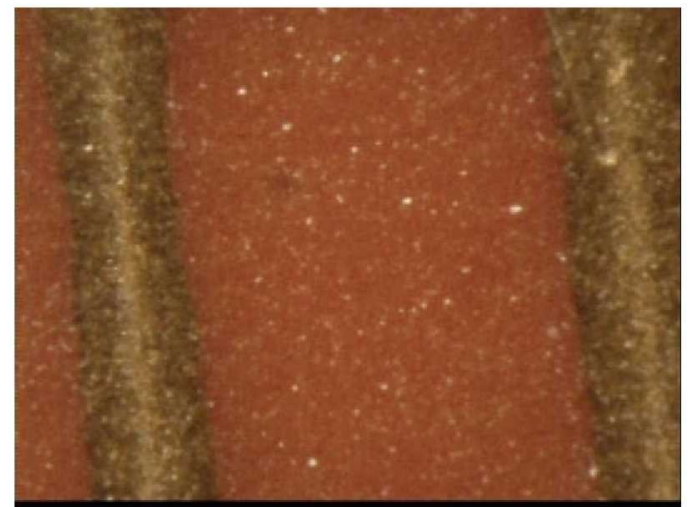

Figure 40: 2010-03-08A - Trip \#2 (9/11/2010)

\section{Conclusions}

Through visual inspection, one can see the impact that both technologies have in dust mitigation. Control 1 and 2 were the easiest to visually inspect due to its white color. The observed difference in dust accumulation between the Control 2 and Control 1 are clearly discernible. The microscopic imaging shows the differences in the amount of particle coverage and particle size of Control 2. This is further supported by the $\Delta \alpha$ based on the solar absorptance measurements taken at the beginning and end of the D-RaTS exposure. The EDS panels also proved to be successful at dust mitigation. The combination of the EDS and Lotus coating improved the dust mitigation properties.

\section{References}

${ }^{1}$ Calle, C.I., A. Chen, C.D., Immer, M. Csonka, M.D. Hogue, S.J. Snyder, M. Rodriguez and D.V. Margiotta, "Dust Removal Technology Demonstration for a Lunar Habitat," Proc. ESA Annual Meeting on Electrostatics (2010)

${ }^{2}$ Margiotta D.V., Peters W.C., Straka S. A., Rodriguiez M., McKittrck K.R., Jones C. B., "The Lotus coating for space exploration- a dust mitigation tool," Proc. SPIE, Vol. 7794 (2010)

${ }^{3}$ McKay, D.S., J.L. Carter, W.W. Boles, C.C. Allen, and J.H. Alton, "JSC-1: A new lunar stimulant," $24^{\text {th }}$ Lunar and Planetary Science Conference, p. 963. 